\title{
Life quality of women with breast cancer after mastectomy or breast conserving therapy treated with adjuvant chemotherapy
}

\author{
Marzena Kamińska', Tomasz Ciszewski', Bożena Kukiełka-Budny ${ }^{1}$, Tomasz Kubiatowski', \\ Bożena Baczewska², Marta Makara-Studzińska', Elżbieta Starosławska', Iwona Bojar ${ }^{4}$ \\ ${ }^{1}$ Clinical Oncology Ward, St. John's Cancer Center, Lublin, Poland \\ 2 Department of Internal Medicine in Nursing, Medical University of Lublin, Poland \\ ${ }^{3}$ Department of Applied Psychology, Medical University of Lublin, Poland \\ ${ }^{4}$ Institute of Rural Health in Lublin, Poland
}

Kamińska M, Ciszewski T, Kukiełka-Budny B, Kubiatowski T, Baczewska B, Makara-Studzińska M, Starosławska E, Bojar I. Life quality of women with breast cancer after mastectomy or breast conserving therapy treated with adjuvant chemotherapy. Ann Agric Environ Med. 2015; 22(4): 724-730. doi: 10.5604/12321966.1185784

\section{Abstract}

Introduction. Breast cancer is the most frequent malignant neoplasm in women. The evaluation of the quality of life has become a treatment parameter as important as survival.

Objective. The aim of the study was evaluation of the quality of life among women treated for breast cancer who underwent surgical procedures using two alternative methods: mastectomy or breast conserving therapy (BCT).

Materials and method. 85 patients treated with BCT and 94 patients who underwent mastectomy were evaluated. Standard questionnaires for the evaluation of the quality of life of cancer patients were used - QLQ-C30 (Quality of life questionnaire - core 30) with QLQ-BR23 (Breast Cancer Module). The Hospital Anxiety and Depression Scale was also applied.

Results. Social and demographic factors (age, education, marital status) influenced the evaluation of the life quality among both groups. Obtained data was also dependent on the type of surgical procedure and chemical treatment. The level of anxiety and depression also influenced the general quality of life and was higher in women who underwent mastectomy. Conclusions. Quality of life plays an important role in the treatment process. Women after BCT declared a higher quality of life compared to patients after mastectomy. The process of making the decision concerning the planned surgical procedure should take into consideration the influence of the intervention on the quality of patients' future life.

\section{Key words}

breast cancer, quality of life, mastectomy, breast conserving therapy, anxiety, depression

\section{INTRODUCTION}

Breast cancer is a serious health and social problem. Worldwide, it is considered to be one of the most prevalent malignant diseases and $34 \%$ of women treated for any neoplasm suffer from it [1]. In 2008 alone, over 1,384,155 new cases were diagnosed and 458,503 persons died as a consequence of the cancer [2].

Breast cancer constitutes a very heterogenous group of neoplasms differing by biological features, clinical course, prognosis and response to treatment. Its treatment is a combined therapy and the sequence and time are established according to accepted standards [3]. The basic rule of the therapeutic process in the early stage of the disease is a surgical procedure complemented with post-operative radiotherapy $(\mathrm{RTH})$, as indicated.

The main purpose of surgical treatment is to obtain oncological radicalness and acquire data indicating the pathological stage of the disease. The following procedures are used in the course of breast surgery: breast conserving therapy (BCT) and mastectomy [4]. Systemic treatment: chemotherapy (CHT) and hormonal therapy (HTH) in conjunction with surgical procedure is used in cases of local advanced disease.

The treatment results depend on the provision of full profile, professional medical care at all stages of diagnostic

Address for correspondence: Iwona Bojar, Institute of Rural Health in Lublin Jaczewskiego 2, 20-090 Lublin, Poland

E-mail: iwonabojar75@gmail.com

Received: 16 October 2013; accepted: 19 December 2014 and therapeutic process. Taking good care of the quality of life of breast cancer patients after oncological treatment is one of the principal World Health Organization (WHO) guidelines [5]. However, the term 'quality of life' is ambiguous, difficult to define, and its understanding depends on one's worldview, education and experiences. The difficulty results from the wide semantic variety of this term in various contexts.

The WHO defines the quality of life as an 'individual's perception of their position in life in the context of the culture and value systems in which they live and in relation to their goals, expectations, standards and concerns' [6]. According to Gotay and Moore [7], 'the quality of life is the ability to conduct daily physical, mental and social functions and getting satisfaction from their performance'. Abnormalities may complicate various diseases, in articular those that are life-threatening, chronic, or involve long-term therapy and/or hospitalization that occurs during most of neoplasmatic disease.

The purpose of evaluating the quality of life in oncology is the monitoring of health care provision to the patients by examining their physical and mental condition, as well as social situation. Apart from the expected positive outcomes, such as full recovery or increasing survival time, there are also disadvantages, e.g. the occurrence of a series of adverse symptoms. Analysis of benefits and detriments of medical intervention and the obtained information concerning the quality of a cancer patient's life may facilitate the application of optimal nursing care and better cooperation between the patient, family and the health care professionals [8]. 


\section{OBJECTIVE}

The aim of the study was evaluation of the quality of life among breast cancer patients who underwent mastectomy or breast conserving treatment with systemic adjuvant therapy. Particular attention was paid to social and demographic factors (age, education, marital status, residence) and their influence on the quality of life and its correlation with both surgical procedures. The difference between the two surgical methods in the scope of physical, social, emotional, cognitive, anxiety and depression level, as well as effects of adverse symptoms on the quality of life, was also studied.

\section{MATERIALS AND METHOD}

The study was conducted according to national law and the protocol was fully approved by St. John's Cancer Centre Review Board and the Ethics Committee of the Medical University in Lublin, Poland.

85 Caucasian women who underwent breast conserving treatment and 94 treated with mastectomy in St. John's Cancer Centre in Lublin, and Oncological Surgery Department of the Medical University in Lublin in 2005-2007 were randomly selected for the study.

Each voluntary participant was personally interviewed by one registered nurse, who explained aims of the study and how to complete the questionnaires. Three standard native (Polish) language questionnaires with written explanations from the European Organization for Research and Treatment of Cancer (EORTC) were applied: QLQC-30 (Quality of life questionnaire - core 30), QLQBR-23 (Quality of life questionnaire - Breast Cancer Module) and HADS (The Hospital Anxiety and Depression Scale). EORTC agreement for using the QLQC-30 and QLQBR-23 in the study was acquired. The authors' own questionnaire attached to the main study and the Majkowicz, de Walden-Gałuszko, Chojnacka-Szawłowska and Magiera adaptation scale [9] were also used in the study.

EORTC QLQC-30 and QLQBR-23 questionnaires were subjected to standardization testing, which confirmed their integrity and credibility $[10,11,12]$.

The base module was the QLQC-30 questionnaire examining the total quality of life in the course of cancer disease: the questionnaire contains 30 questions consisting of 5 scales, each one evaluating the patient's functioning on the physical, emotional, cognitive, social and economic level. The questionnaire is based on the self-evaluation method, includes simple questions that are easy to understand after translation into other languages, and can be used in various social conditions [10].

The organ module, specific for the breast, was provided by QLQBR-23 questionnaire. EORTC QLQ-BR23 which contains 23 questions grouped within 4 functional scales (own body image, sexual function and satisfaction, as well as future perspectives), and 4 symptom scales (evaluation of side-effects of the treatment, afflictions from arm and breast, as well as hair loss) [11].

HADS scale is used for the screening of oncological patients for anxiety and depression [13].

The characteristics of the study group were prepared using basic demographic data. The analyzed data were described, depending on the distribution, with either medial or average value, as well as percentile range or standard deviation. In order to analyze the differences between the two groups, nonparametric statistics module tests were used, namely, Mann-Whitney U test and Kolmogorov-Smirnov test, respectively. In order to define the differences in the preferences of particular subpopulations, the McNemara $\mathrm{chi}^{2}$ test was used. Calculations were conducted for the $95 \%$ confidence interval $(95 \% \mathrm{CI})$, The 0.05 level of probability $(p<0.05)$ was used as the criterion of significance.

\section{RESULTS}

The influence of social and demographic factors on the quality of life - age and quality of life. For the analysis, the patients were divided into two age groups: 30 - 45 years of age and $45-70$ years of age. The only significant difference observed was the higher evaluation of 'sexual functioning' in the group of patients aged $45-70$ after BCT, compared to the group of patients aged $30-45$. Similarly, a higher evaluation of 'sexual functioning' was found in the group of patients aged $45-70$ after mastectomy, compared to the group of patients aged $30-45$ (Fig. 1A). Differences were also observed in the prognosis of patients' own health. Patients aged 30 - 45 who had undergone either BCT or mastectomy assessed their own health prognosis worse than the patients aged $45-70$.

The above described analysis of the study material shows that patients aged $30-45$ were more worried about prognosis and their future, were anxious about the influence of the disease on their family life and the relationship with their partner (Fig. 1B).

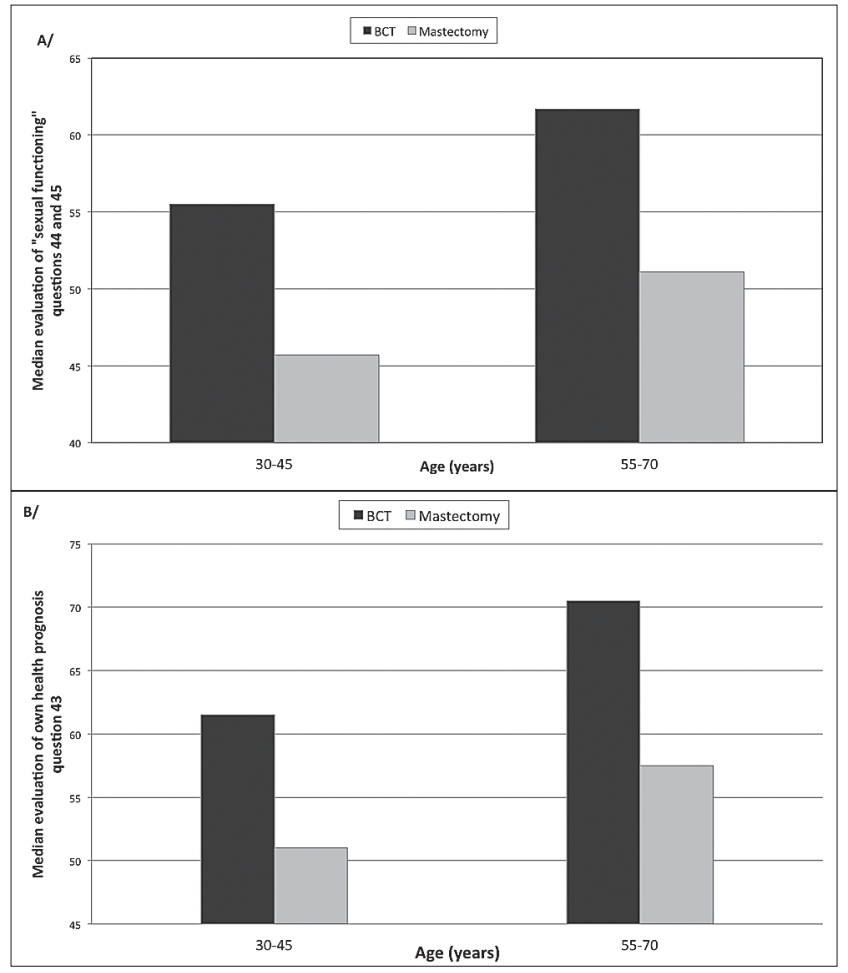

Figure 1. Evaluation of "sexual functioning" in the group of patients after mastectomy and BCT who underwent systemic adjuvant treatment, prepared on the basis of questions 44, 45 of QLQ BR-23 questionnaire in relation to age (A) and assessment of own health prognosis of patients after either mastectomy or $B C T$ who had undergone systemic adjuvant treatment prepared on the basis of question 43 of QLQ BR-23 questionnaire in relation to age (B) 
Education and quality of life. For statistical purposes, the population was divided according to declared level of education. Three groups of patients were formed, with higher, secondary and vocational education. Analysis shows that the patients with higher education after BCT evaluated their physical condition and social functioning much higher than patients with secondary and vocational education. The lowest score in the 'financial problems' scale was observed in the group of patients with vocational education (Fig. 2, plots A, $\mathrm{B}$ and $\mathrm{C})$.

The above presented analysis shows that the level of patients' education influenced their physical and social functioning. A higher level of education was directly connected with a wider scope of knowledge, which facilitated better adaptation and acceptance of the disease. Women with a lower level of education more frequently reported difficulties with their

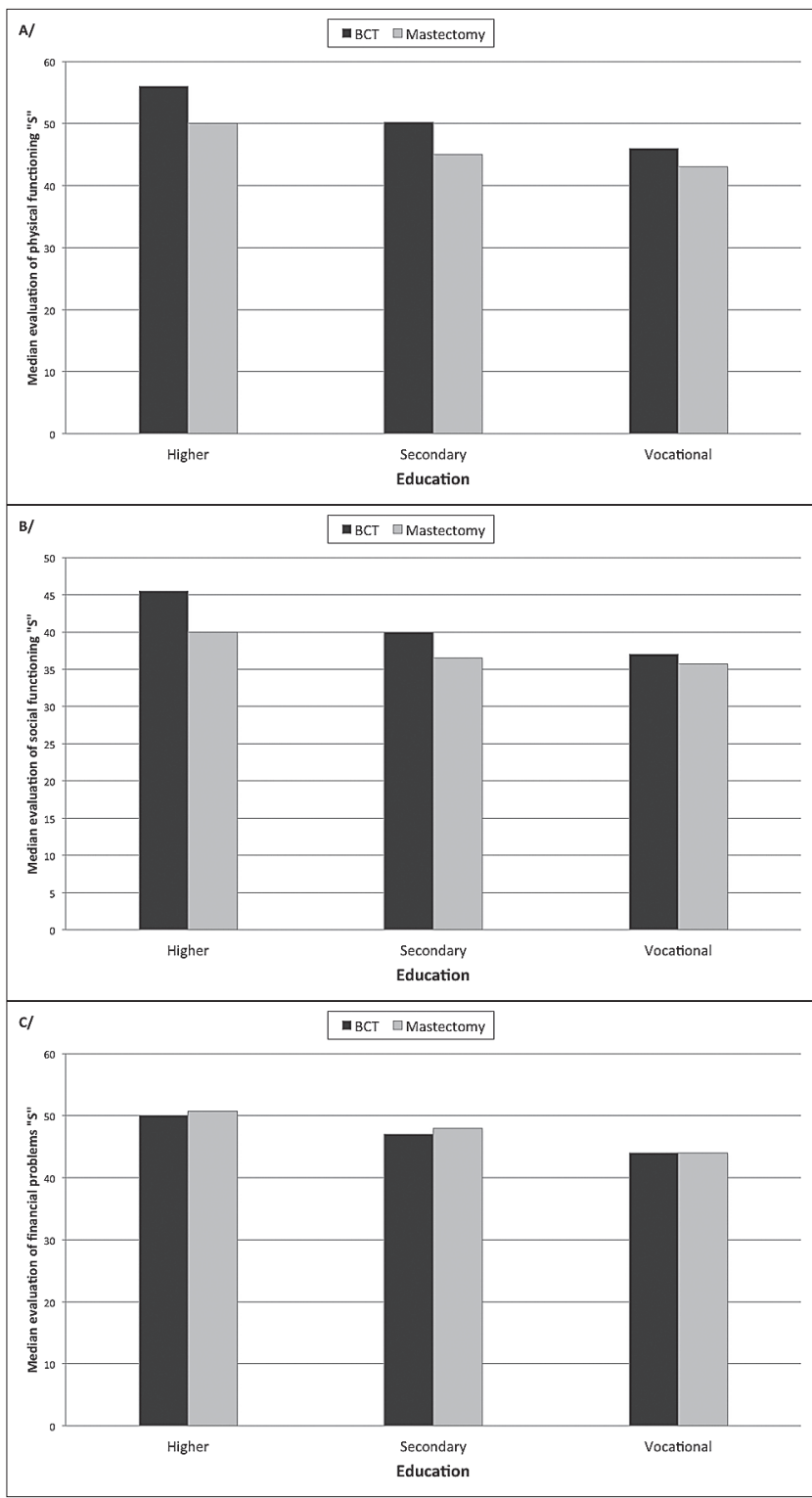

Figure 2. Evaluation of physical functioning in the group of patients after either mastectomy or BCT who had undergone systemic adjuvant treatment, prepared on the basis of questions 1-5 of QLQ C-30 questionnaire in relation to education (A), social functioning in the group of patients after either mastectomy or BCT who had undergone systemic adjuvant treatment, prepared on the basis of questions 6-7-26-27 of QLQ C-30 questionnaire in relation to education (B) and evaluation of financial problems prepared on the basis of question 28 of QLQ C-30 questionnaire in relation to education (C) ability to work, as well as every day activities and social functioning.

At the same time, higher education and work status directly influenced the patients' financial status. In the group of women with vocational education, financial difficulties constituted an additional problem. Disease limited the patients' professional capability which led to a decrease in the family's income. The costs of treatment, including transportation and additional care, constituted a burden for the household budget.

Residence and quality of life. For the statistical analysis, three subgroups of patients were formed: city dwellers (population $\geq 20,000$ ), town dwellers (population $<20,000$ ) and country dwellers. From the total number of 135 patients, the largest number, 116 women, lived in cities and large towns, 19 lived in small towns and 44 lived in the country. The only difference was observed in the case of lower evaluation of their physical functioning by patients living in rural area (Fig. 3A).

The only statistically significant difference was observed in the case of lower evaluation of their physical functioning by patients living in rural area. For women living in the country, physical capability very often defined their role and usefulness.

Marital status and the quality of life. The study population was divided into two subgroups: a group of married women and a group of maidens, widows and divorced women. Higher evaluation of their own body image was observed

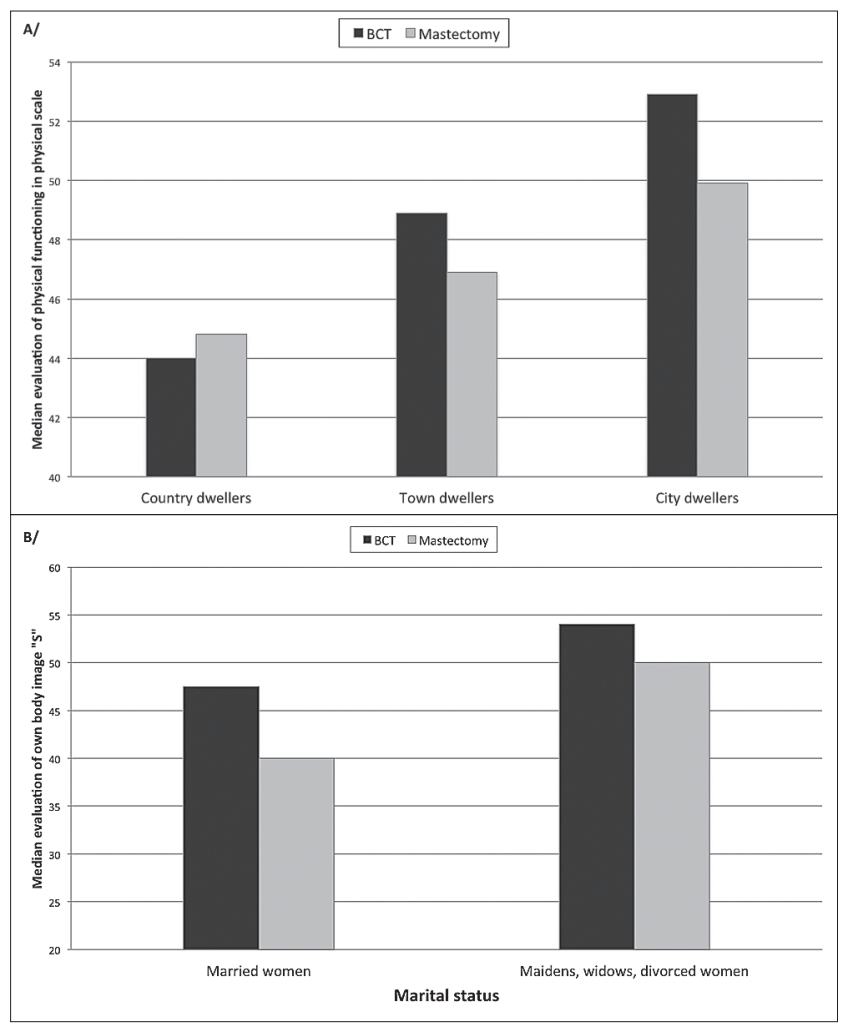

Figure 3. Evaluation of physical functioning in the group of patients after either mastectomy or BCT who had undergone systemic adjuvant treatment, prepared on the basis of questions 1-5 of QLQ C-30 questionnaire in relation to residence (A) and evaluation of own body image in the group of patients after mastectomy or BCT who had undergone systemic adjuvant treatment, prepared on the basis of questions 39-40-41-42 of QLQ BR 23 questionnaire in relation to marital status (B). 
in unmarried women, both after BCT and mastectomy (Fig. 3B). A higher evaluation of own body image was observed in unmarried women, both after BCT and mastectomy.

Influence of physical, social, cognitive and emotional functioning on the quality of life. Disease and a long therapeutic process often affect the whole organism, interfere with normal functioning, and cause temporary or permanent withdrawal from some social roles and forms of activity. The questions concerning physical functioning (Fig. 4, plot A) showed statistically significant differences $(\mathrm{p}<0.001)$ between the patients' evaluation of their own physical condition; the best physical functioning was declared by patients after BCT.

The questions concerning social functioning (Fig. 4, plot B) showed statistically significant differences $(\mathrm{p}<0.001)$ between the patients' evaluation of their own social functioning; the

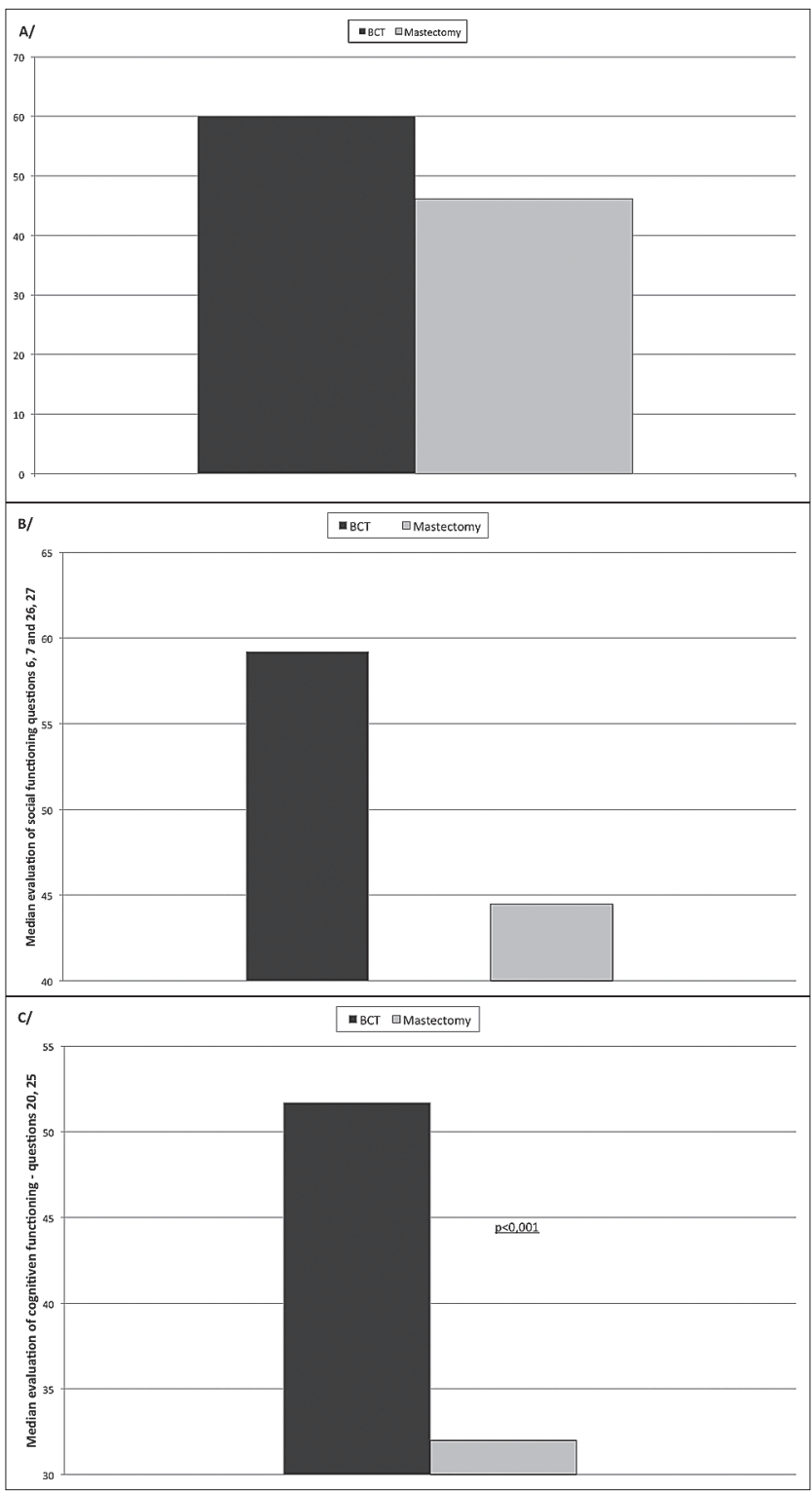

Figure 4. Graphic analysis of the evaluation of physical functioning in the group of patients after mastectomy and BCT subjected to systemic adjuvant treatment prepared on the basis of QLQ C-30 questionnaire (questions 1-5) (A), social functioning in the group of patients after mastectomy and BCT subjected to systemic adjuvant treatment prepared on the basis of QLQ C-30 questionnaire (questions 6-7-26-27) (B) and evaluation of cognitive functioning in the group of patients after mastectomy and BCT subjected to systemic adjuvant treatment prepared on the basis of QLQ C-30 questionnaire (questions 20,25) (C) best physical functioning was declared by patients after BCT.

The questions concerning emotional functioning (Fig. 5, plot A) showed statistically significant differences $(\mathrm{p}<0.001)$ between the patients' evaluation of their own emotional condition; the best emotional functioning was declared by patients after BCT.

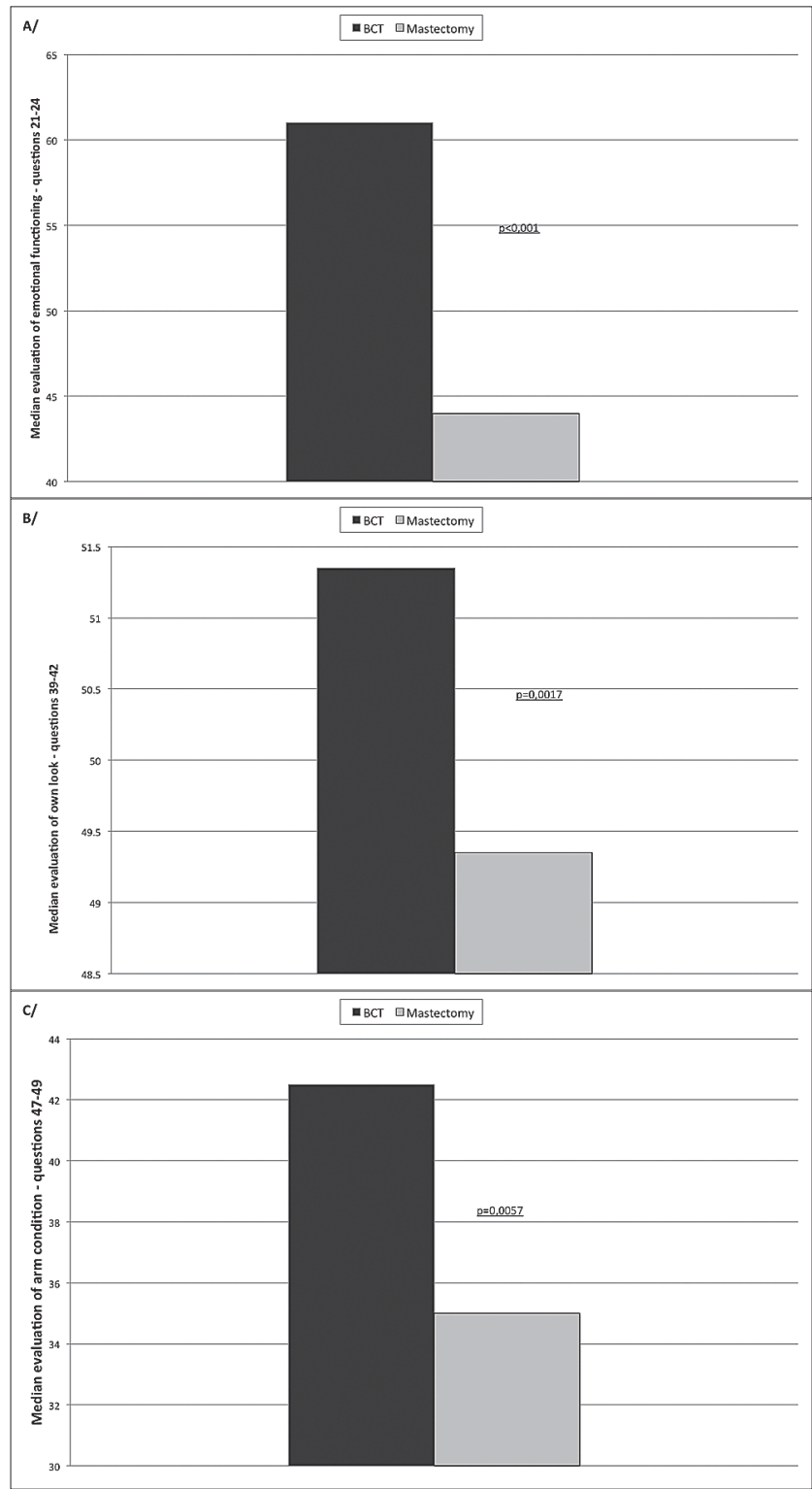

Figure 5. Evaluation of emotional functioning in the group of patients after mastectomy and BCT subjected to systemic adjuvant treatment prepared on the basis of QLQ C-30 questionnaire (questions 21-24) (A), own looks in the group of patients after either mastectomy or BCT who had undergone systemic adjuvant treatment, prepared on the basis of QLQ BR 23 questionnaire (questions 39-42) (B) and evaluation of "arm condition" in the group of patients after either mastectomy or BCT who had undergone systemic adjuvant treatment, prepared on the basis of QLQ BR 23 questionnaire (questions 47-49) (C)

Impact of surgical procedure on the quality of life. Questions 39-42 showed statistically significant differences $(p<0.001)$ between the patients' evaluation of their own looks; the best assessment of their looks was declared by patients after BCT. Statistically significant differences $(p=0.0057)$ were also found in the evaluation of the 'arm condition' between the patients who had undergone different surgical procedure: either mastectomy or BCT. Better 'arm condition' was declared by patients after BCT. (Fig. 5, plots B and C). 
Influence of side-effects on the quality of life. On the basis of questions from QLQ C-30 and QLQ BR-23 questionnaires, side-effects of anti-cancer therapy were identified. The analysis showed that the most burdensome symptoms accompanying the systemic treatment were: nausea and vomiting, and they were the most intensive in the group of patients after mastectomy (Fig. 6).

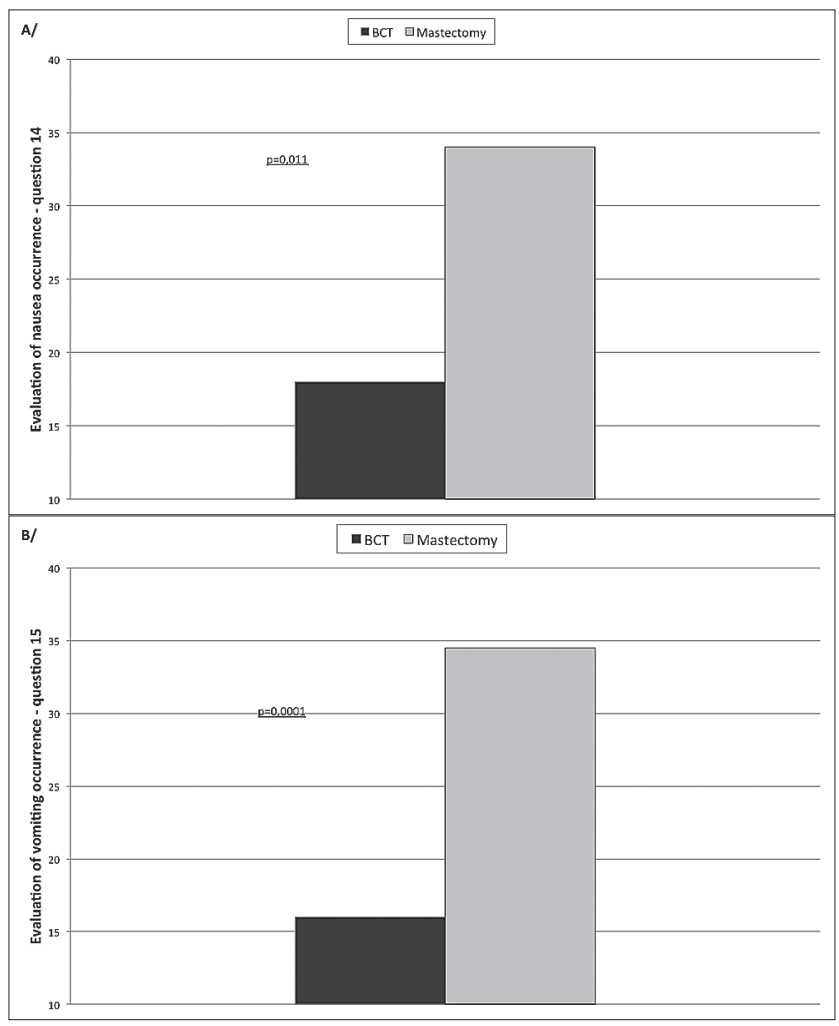

Figure 6. Occurrence of nausea in patients after mastectomy and BCT subjected to systemic adjuvant treatment prepared on the basis of QLQ C-30 questionnaire (question 14) (A) and vomiting in patients after mastectomy and BCT subjected to systemic adjuvant treatment prepared on the basis of QLQ C-30 questionnaire (question 15) (B)

Influence of anxiety and depression on the quality of life. Analysis of the data presented in Figure 16 shows that the level of anxiety in patients after mastectomy reached the value of 7.8 scale points, while in patients after BCT the value was 6.96 scale points. In the case of depression, the values were

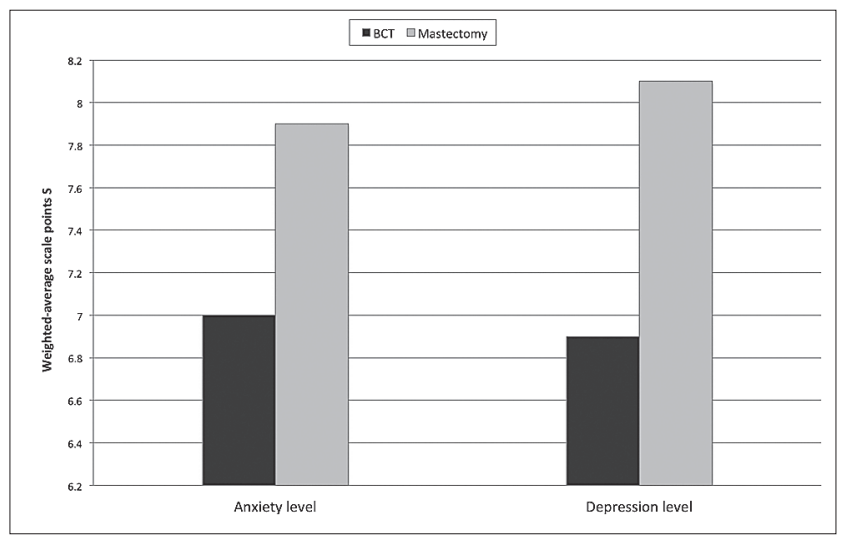

Figure 7. Comparison of the level of anxiety and depression based on HADS questionnaire in the groups of patients after surgical procedures: either mastectomy or BCT who had undergone systemic adjuvant treatment as follows: 8.04 scale points in patients after mastectomy and 6.8 scale points in patients after BCT. The differences were statistically significant (Mann-Whitney U test $\mathrm{p}<0.01$ ).

\section{DISCUSSION}

Breast cancer leads to significant deterioration in the quality of life. Through observation of patients suffering from cancer disease it is obvious that the quality of life is a treatment parameter just as important as survival.

The complexity of issues connected with the concept of the quality of life is more often investigated by various groups of medial workers, including doctors, nurses, psychologists, sociologists and physiotherapists. These studies are conducted in order to consolidate the interdisciplinary activities leading to the improvement of the life quality, especially in patients diagnosed with a malignant disease [14].

Breast cancer therapy is dependent on the stage of the disease. Surgical treatment is the basic therapeutic procedure in breast cancer patients, for which two methods are used: breast conservation and mastectomy. The method more frequently chosen today, both in Poland and worldwide, is the breast conserving treatment which allows women to keep their organ, enjoy a better quality of life, and is equally effective in treating the disease $[15,16]$. However, due to the lack of a fully effective screening programme and low proportion of early breast cancer cases, BCT is applied much less frequently in Poland than in Western Europe countries [17].

Breasts are one of the attributes of femininity and their loss in the case of breast cancer is a traumatic psychological experience. Women diagnosed with breast cancer are a very specific population, in which discomfort caused by the disease significantly influences their functioning in everyday private, social and professional life.

The presented study reveals a significant correlation between education and assessment of the quality of life in the group of patients with higher education who had undergone BCT. They were characterized with better physical and social functioning. Patients with secondary education were characterized with a worse assessment of their quality of life in the same categories as patients with higher education. Analogically, their assessment of their quality of life was significantly higher than patients with vocational education.

Similar data was presented by Ganz et al. [18] who reported that better perception of general health status was connected with higher level of education, better physical and emotional functioning, a smaller number of coexisting diseases, lower vulnerability, and avoidance of menopause caused by treatment. Janz et al. [19] confirmed a positive correlation between the evaluation of the quality of life and higher level of patients' education among early stage breast cancer patients.

In the group of patients with vocational education, it was observed that the disease and treatment led to intensification of financial problems. Professional activity is closely connected with the quality of life. Career is a factor that motivates to sustaining activity and fitness, and disease limits the professional opportunities decreasing the household income. According to the current data, among younger patients, after both BCT and mastectomy, the assessment of their own health status was worse than in the group of older patients. Moreover, statistical analysis of the survey data showed that 
younger women assessed their sexual functioning as worse to a higher degree than older women. On the other hand, Pacian et al. [20] found that breast cancer patients aged 45 - 50 years better assessed their functioning in all studied areas, compared with older respondents.

Fobair et al. [21] noticed that the method of surgical treatment used, either breast conservation or mastectomy, was a significant factor influencing the perception of a women's own body. Analysis of the study material revealed statistical significance in the correlation between the assessment of patients' own appearance and their marital status. It is quite surprising that the unmarried patients after BCT assessed their appearance as better to a higher degree than those who were married.

The current study also confirmed previous data that breast conserving treatment is correlated with better self-assessment of patients' appearance $[15,16]$. The body image constitutes a foundation for self-esteem, while mastectomy is associated with disfigurement, loss of femininity, attractiveness and maternity. Moreover, loss of a breast may lead to anxiety connected with lack of acceptance from the partner, or even the breakup of a family.

As found in the presented study, the sole diagnosis of breast cancer, long-time treatment and recovery cause many problems which accumulate over time, involving decrease in self-esteem, change of body image, occurrence of anxiety and depression, emotional disturbances and, in consequence, impairment of sexual functions [21]. Additional adverse experiences are associated with loss of hair, nausea and vomiting, loss of appetite, fatigue and insomnia in the course of chemotherapy, or excess weight, flushing and anxiety. In this study, a few symptoms significantly worsened the quality of patients' life: insomnia, fatigue and financial problems. Similar results were obtained by other researchers in longterm studies [22].

It should be also pointed out that in course of treatment with cytostatic drugs and upon completion of chemotherapy, the quality of life is significantly decreased, as indicated by the majority of functional and symptomatic scales. Among the studied group the most burdensome side-effects of oncological treatment was nausea and vomiting. Ioannidis et al. [23] also noticed that patients undergoing chemotherapy most often complained about nausea and vomiting, and were the side-effects they feared most. The side-effects of the applied treatment may persist for many years after completion of the treatment, and are connected with the decrease in the quality of life expressed by worse physical and mental condition, and interference with the realization of life plans.

On the basis of own analysis, it can be stated that patients after mastectomy evaluate the condition and functioning of their arm on the operated side more negatively, compared to women after BCT. The complications of surgical procedure may include: sensitivity impairment in the scar area, the occurrence of fibrosis and contractures limiting mobility of the shoulder joint, lymphatic oedema and postural defects. Rietman et al. [24] reported that women after mastectomy were characterized by decreased functionality, and more frequently complained of upper limb pain on the operated side.

The presented study also showed that a higher degree of anxiety and depression was observed in women after mastectomy, and the physical changes were accompanied by adverse mental changes: the women felt imperfect and were characterized by the so-called 'partial woman' complex [25].

Examination of the level of anxiety and depression among women treated for breast cancer resulted in obtaining measurable results of the treatment and general nursing procedures. The current study confirmed that the anxiety and depression experienced by patients after surgical procedures were not only features of the patients' personality, but they were also unpleasant phenomena accompanying the patients' daily struggle with the disease.

The scope of the presented study did not permit the involvement of all aspects of the patients' lives, and does not fully reflect an objective evaluation of its quality. It only allows for subjective analysis of the health status of patients treated for breast cancer with either BCT or mastectomy, followed by chemotherapy. This is very important because it is an individual assessment made by the patients themselves, and allows for acquainting oneself with the patients' physical status, mental condition and social circumstances. It also contains self-evaluation of the realization of certain tasks in relation to the perception of the patients' own health status. Another, important limitation is the relatively small size of the examined groups; however it is similar to most of the above-cited studies.

The obtained results show a relatively good quality of life of women after BCT, which makes breast conservation the preferred method of surgical treatment as it is accompanied by a significantly smaller number of adverse effects.

\section{CONCLUSIONS}

1. The analysis presented above served as the basis for the formulation of the following conclusions:

2. The declared quality of life is significantly better in the group of patients after breast conserving treatment, compared to the patients who underwent mastectomy, since a conserved breast is an attribute of femininity and positively influences the self-evaluation of a woman's appearance and treatment prognosis.

3. The quality of life of women treated for breast cancer were influenced by social and demographic factors. Older patients after breast conserving treatment evaluated their sexual functioning more highly, and expressed higher expectations for the positive treatment outcome than patients after mastectomy. A higher level of education of women after BCT meant better physical and social functioning, compared to women with secondary or vocational education who had undergone mastectomy. Patients with vocational education who had undergone mastectomy had their financial problems intensified by the disease. Moreover, unmarried patients after BCT had better body image than married women.

4. Evaluation of the quality of life was significantly higher in the group of patients after breast conservation, and concerned such spheres of life as: physical, social, cognitive and emotional functioning, compared to women after mastectomy.

5. Decreased quality of life of women treated with either BCT or mastectomy followed by chemotherapy was the result of side-effects of oncological treatment, especially nausea and vomiting, which adversely influenced the comfort of living. The side- effects were intensified in women who had undergone mastectomy. 
6. The symptoms of anxiety and depression had an adverse impact on the evaluation of the quality of life of women treated for breast cancer. They were more pronounced or even dominant in women after mastectomy.

7. A relatively good quality of life was found among women who underwent BCT, which allows the recommendation of this method of surgical treatment as it is accompanied by a significantly smaller number of adverse effects.

\section{REFERENCES}

1. Calonge N, Petitti DB, DeWitt TG, Dietrich AJ, Gregory KD, Grossman D. US Preventive Services Task Force. Screening for breast cancer: US Preventive Services Task Force recommendation statement. Ann Intern Med. 2009; 151(10): 716-726.

2. Globocan 2008. Fast Stats. Most frequent cancers: women. Retrieved from: http://globocan.iarc.fr/factsheets/populations/factsheet. asp? uno=900\#WOMEN (access: 2013.08.28).

3. Aebi S, Davidson T, Gruber G, Cardoso F. Primary breast cancer: ESMO Clinical Practice Guidelines for diagnosis, treatment and follow-up. Ann Oncol. 2011; 22(Supplement 6): vi 12-vi24.

4. Bishop H, Chan C, Monypenny I, Patnick J, Sibbering M, Watkins R, Winstanley J, Bundred N, Corder A, Nicholson S, Robertson J, Rothnie N, Davies L. Surgical guidelines for the management of breast cancer. Eur J Surg Oncol. 2009; 35(Suppl 1): 1-22.

5. WHOQOL Group. Study protocol for the World Health Organization. Project to develop a quality of life assessment instrument. Qual Life Res. 1993; 2(2): 153-159.

6. World Health Organization. Report of WHOQOL Focus Group Work. World Health Organization, 1993; Geneva.

7. Gotay CC, Moore TD. Assessing quality of life in head and neck cancer. Qual Life Res. 1992; 1(1): 5-17.

8. Honea NJ, Brintnall R, Given B, Sherwood P, Colao DB, Somers SC, Northouse LL. Putting evidence into practice: nursing assessment and interventions to reduce family caregiver strain and burden. Clin J Oncol Nurs. 2008; 12(3): 507-516.

9. Majkowicz M, Chojnacka-Szawłowska G. Metodologiczne problemy badania jakości życia. In: de Walden-Gałuszko, K., Majkowicz, M. Jakość życia w chorobie nowotworowej. Gdańsk, 1994; Wydawnictwo Uniwersytetu Gdańskiego (in Polish).

10. Aaronson NK, Ahmedzai S, Bergman B, Bullinger M, Cull A, Duez NJ, Filiberti A, Flechtner H, Fleishman SB, de Haes JC, et al. The European Organization for Research and Treatment of Cancer QLQ-C30: a quality-of-life instrument for use in international clinical trials in oncology. J Natl Cancer Inst. 1993; 85(5): 365-376.

11. Sprangers MA, Groenvold M, Arraras JI, Franklin J, te Velde A, Muller M, Franzini L, Williams A, de Haes HC, Hopwood P, Cull A, Aaronson
NK. The European Organization for Research and Treatment of Cancer breast cancer-specific quality-of-life questionnaire module: first results from a three-country field study. J Clin Oncol. 1996; 14(10): 2756-2568.

12. Zawisza K, Tobiasz-Adamczyk B, Nowak W, Kulig J, Jędrys J. Validity and reliability of the quality of life questionnaire (EORTC QLQ C30) and its breast cancer module (EORTC QLQ BR23). Ginekol Pol. 2010; 81(04): 262-267.

13. Zigmond AS, Snaith RP. The Hospital Anxiety and Depression Scale. Acta Psychiatr Scand. 1983; 67(6): 361-370.

14. Groenvold M. Health-related quality of life in early breast cancer. Dan Med Bull. 2010; 57(9): B4184.

15. Arndt V, Stegmaier C, Ziegler H, Brenner H. Quality of life over 5 years in women with breast cancer after breast-conserving therapy versus mastectomy: a population-based study. J Cancer Res Clin Oncol. 2008; 134(12): 1311-1318.

16. Han J, Grothuesmann D, Neises M, Hille U, Hillemanns P. Quality of life and satisfaction after breast cancer operation. Arch Gynecol Obstet. 2010; 282(1): 75-82.

17. Maślach D, Krzyżak M, Szpak A, Bojar I, Bielska-Lasota M, Owoc A. The breast-conserving surgery of women with breast cancer in Podlaskie Voivodeship (Poland). Population study. Ann Agric Environ Med. 2013; 20(2): 395-400.

18. Ganz PA, Kwan L, Stanton AL, Krupnick JL, Rowland JH, Meyerowitz BE, Bower JE, Belin TR. Quality of life at the end of primary treatment of breast cancer first results from the moving beyond cancer randomized trial. J Natl Cancer Inst. 2004; 96(5): 376-387.

19. Janz NK, Mujahid M, Lantz PM, Fagerlin A, Salem B, Morrow M, Deapen D, Katz SJ. Population based study of the relationship of treatment and sociodemographics on quality of life for early stage breast cancer. Qual Life Res. 2005; 14(6): 1467-1479.

20. Pacian A, Kulik TB, Pacian J, Chruściel P, Żołnierczuk-Kieliszek D, Jarosz MJ. Psychosocial aspect of quality of life of Polish women with breast cancer. Ann Agric Environ Med. 2012; 19(3): 509-512.

21. Fobair P, Stewart SL, Chang S, D`Onofrio C, Banks PJ, Bloom JR. Body image and sexual problems in young women with breast cancer. Psychooncology. 2006; 15(7): 579-594.

22. Waldman A, Pritzkuleit R, Raspe H, Katalinic A. The OVIS study: health related quality of life measured by the EORTC QLQ-C30 and-BR23 in German female patients with breast cancer from Schleswig-Holstein. Qual Life Res. 2007; 16(5): 767-776.

23. Ioannidis JP, Hesketh PJ, Lau J. Contribution of dexamethasone to control of chemotherapy-induced nausea and vomiting: A metaanalysis of randomized evidence. J Clin Oncol. 2000; 18(19): 3409-3422.

24. Rietman JS, Dijkstra PU, Hoekstra HJ, Eisma WH, Szabo BG, Groothoff JW, Geertzen JH. Late morbidity after treatment of breast cancer in relation to daily activities and quality of life: a systematic review. Eur J Surg Oncol. 2003; 29(3): 230-238.

25. Zegarski W, Głowacka I, Ostrowska Z. Ocena jakości życia kobiet po mastektomii na podstawie standardowych kwestionariuszy: QLQ-C30 i QLQ-BR23. Nowotwory. 2010; 60(6): 532-535. 